\title{
Analysis of Granulometry Influence on Magnesite Thermal Treatment
}

\author{
M. TRUCHLÝ, J. Mikula \& V. Šindler \\ Development and realization workplace of raw materials extracting and treatment, Technical University of \\ Kosice, Němcovej 32, 04384 Košice, Slovakia
}

\begin{abstract}
For the granular materials thermal treatment, the material granulometry belongs to the principal factors influencing furnace performance and product quality. Mathematical modelling belongs to the basic tools of their research and operation. The paper presents the mathematical model adaptation for thermal processing of magnesite based on the method of elementary balances. The calibration has been used to ensure an adequacy of the processes. Developed mathematical model based on abstraction charge massivity can in very simplified form take account on actual situations.
\end{abstract}

KEYWORD: magnesium; magnesite; granulometry; simulation; mathematical modeling

\section{INTRODUCTION}

Magnesite is a basic raw material for carbonate industry. Its direct use for obtaining caustic and sintered magnesia after heat treatment is accomplished. The heat treatment of magnesia is carried out in shaft and rotary furnaces which are suitable for the materials with higher particle sizes and for deck furnaces for the materials with lower particle sizes. Currently new aggregates operating on the principle of compact thin layer and hydraulicmechanical fluidized layer are developed (Koštial 2005).

Research, design, and operation of these devices are based on mathematical modeling. The basic factors affecting parameters of devices and the product quality include grain size of magnesite. The grain size affects the homogeneity of the heat treatment and thus its quality. In terms of adequacy of the model, the basic parameters are density, coefficient of heat transfer, heat exchange area and duration of the process. The contribution is aimed at determining the influence of granularity on homogeneity of the calcination and sintering process.

Inhomogenity of grain size in terms of Shaft furnaces of SMZ, a.s. Jelšava theoretically represents max and min grain size ratio of 150:40 (Košinár 2011). Instability of charged material causes different problem and complications affecting optimal work of shaft furnaces like (Koštial 2005 \& Koštial 2008):

- reduction of permeability of the processed material - concentrate already in area where calcination of magnesite does not occur,
- different sintering time of each grain causes need of unnecessary time protraction for sintering time of material with lower granulometry which are being melted,

- disintegrating of grains during the calcination is critical in terms of hydromechanical processes. Increase of dust ratio of total charge mass causes decreasing of operational indexes of shaft furnaces.

Laboratory devices allow to obtain the necessary information in real time.

Research on heat treatment of magnesite in thermal equipment leads to the following stages:

- heating of the material and moisture evaporation,

- calcination,

- heating to reach the sintering temperature,

- sintering,

- cooling of clinker.

Each phase is involved in the resulting product quality.

\subsection{Laboratory determination of heat transfer coefficient for the mathematical model}

Experimental data were acquired on the laboratory furnace (see Figure 1). The samples of magnesite were heated on the furnace temperature of $300^{\circ} \mathrm{C}$. The objective of the experiment was to investigate influence of the charge granularity on the calculation time of the temperature in the grain middle. Samples of magnesite, caustic magnesia and sintered magnesia were heated from the surface to the center of the sample. Monitored parameter was grain thermal conductivity. The experiments were executed on the laboratory furnace Nabertherm 
P300. Individual samples were heated from the temperature $\sim 20^{\circ} \mathrm{C}$ on $300^{\circ} \mathrm{C}$. Granularity class of the individual samples was $<0.5 \mathrm{~mm}$ with a volume of about $30 \mathrm{~cm}^{3}$ (Olijár 2011).

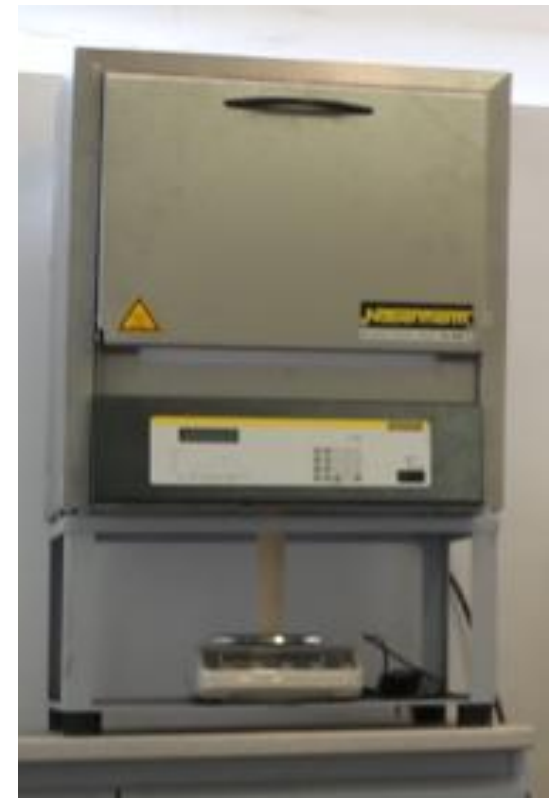

Figure 1 Laboratory furnace Nabertherm P300.

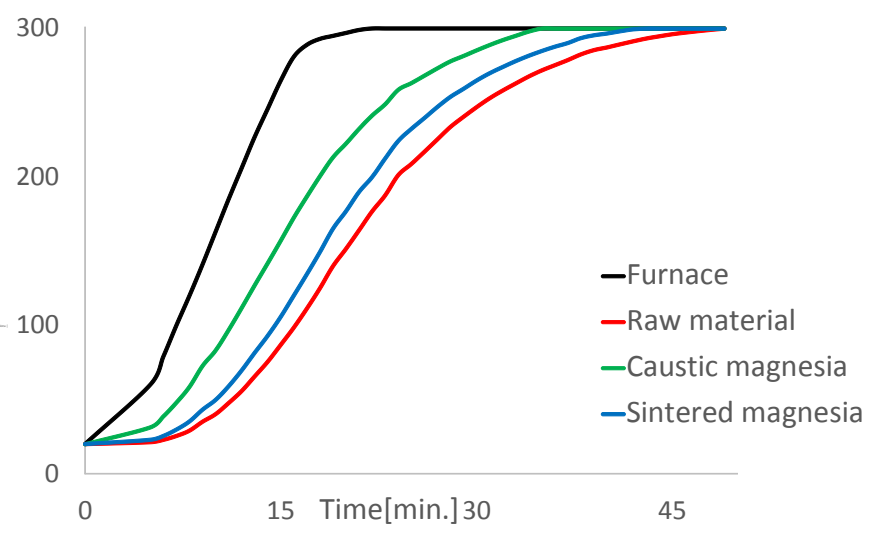

Figure 2. Laboratory determination of rate of heat transfer

In Figure 2 is given a course of temperatures of the furnace and material each of which represents one stage of heat treatment of magnesite.

Based on the results of the experiment, the factor of thermal conductivity for the individual samples has been determined:

- raw material - 3,5 W. $\mathrm{m}^{-1} \cdot \mathrm{K}^{-1}$,

- caustic - $6 \mathrm{~W} \cdot \mathrm{m}^{-1} \cdot \mathrm{K}^{-1}$

- clinker $-4,5 \mathrm{~W} \cdot \mathrm{m}^{-1} \cdot \mathrm{K}^{-1}$.

In the area of validity of the coefficients, the phases of magnesite heat treatment process of the sintered magnesite production in rotary furnaces shown in Figure 3 are obtained.

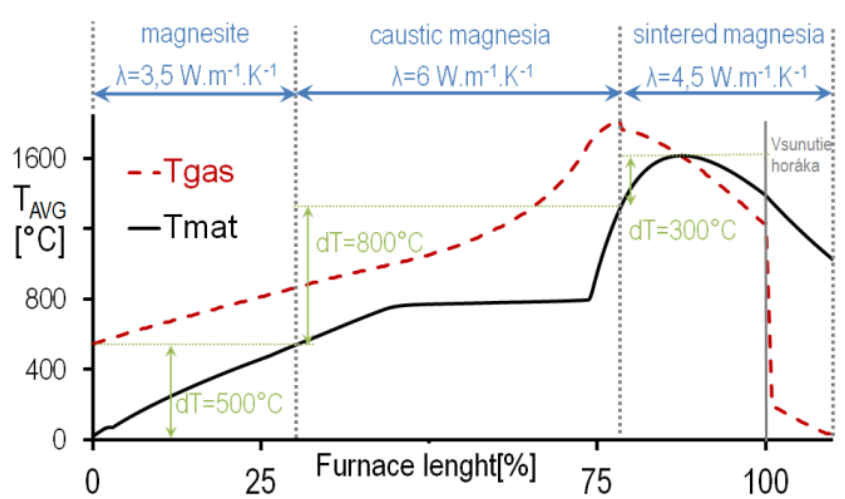

Figure 3. Course of temperatures and phases of production process of the sintered magnesia.

\section{MATHEMATICAL MODEL}

For the research of the charge granularity influence of the process behavior mathematical model was created. Model was based on the primary principles involving heat conduction, heat transfer, heating, calcination, sintering (Mikula 2009). Based on the executed experiments the parameters of the model were determined.

Model library contains the following models of:

- transfer processes,

- heat conduction and convection,

- mass diffusion and convection,

- heat and mass accumulation,

- transformation processes,

- heat generation by combustion,

- evaporation and condensation,

- carbonate dissociation.

Model represents aggregate decomposed on zones which have equal parameters. Each zone is decomposed on layers which consist from elements (Figure 4). Material and thermal balance is executed for each element [Koštial 2006].

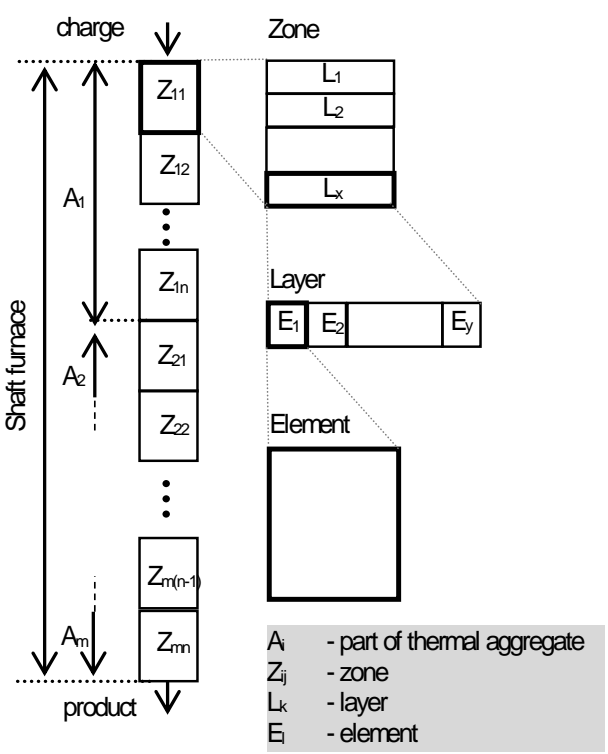

Figure 4. Hierarchical decomposition of simulation model 


\subsection{Basic model of heat conduction}

Heat conduction $Q_{\mathrm{k}}[\mathrm{J}]$ in the material describes fundamental relationship (Koštial 2013 \& Mikula 2009):

$$
Q_{k}=S_{v} \lambda \frac{d t}{d x}
$$

where $\lambda$ material thermal conductivity $\left[\mathrm{W} \cdot \mathrm{m}^{-1} \cdot \mathrm{K}^{-1}\right]$, $\frac{d t}{d x}$ - temperature gradient $\left[\mathrm{K} \cdot \mathrm{m}^{-1}\right], \mathrm{S}_{\mathrm{v}}$ stands forheat surface $\left[\mathrm{m}^{2}\right]$.

\subsection{Grain separation methods}

For monitoring of the heat treatment homogeneity the model of the individual grains were developed. The heat transfer parameters were determined for the individual grains. Sphere is considered as an idealized grain. For the calculation of heat conduction transfer, grain can be classified according to:

- distance (see Figure. 5a),

- weight (see Figure 5b). a)

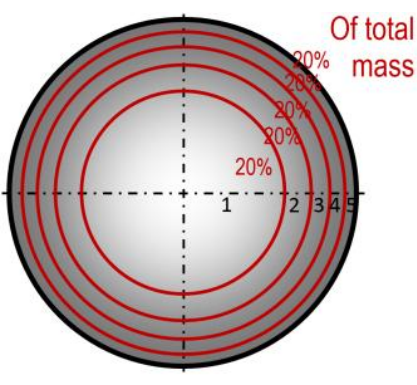

b)

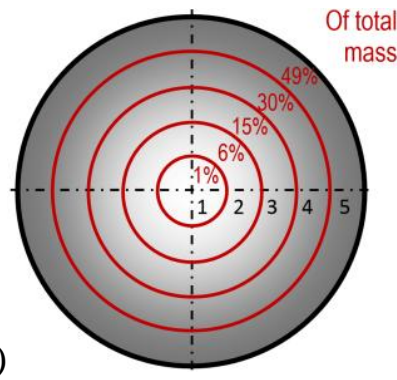

Figure 5 Comparison of grain division of spherical shape under a) constant distance; b) constant weight.

A division according weight was chosen for objectivity of the results. When it is divided under distance, there would be very big weight difference between the first and the last division. For instance, in the case of division into 5 parts, internal division would have $49 \mathrm{x}$ less weight than external layer (see Figure 5). This would distort the results because $1 \%$ of weight insufficiently represents the quality of the heated material.

\subsection{Simulation of heat conduction in the magnesite grain}

Developed mathematical model was applied for the determination of the calcination time dependent on the charge granularity. Laboratory verification is generally carried out in explicit field of investigation. Figure 6 represents courses of magnesite grains heating due to the grain size based on mathematical simulation.

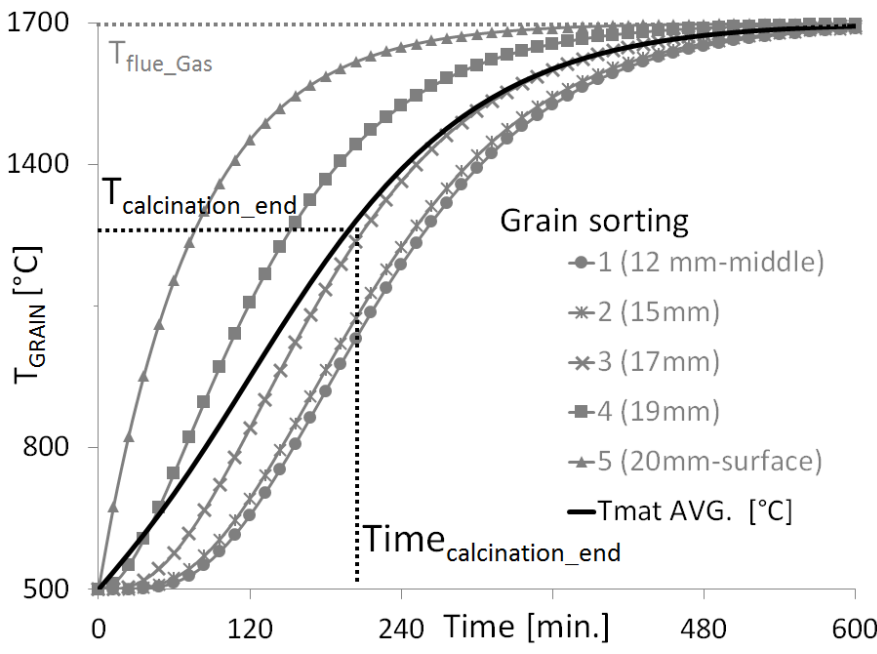

Figure 6. Caustic - heating of grain at a time, diameter100 mm.

Figure 7 represents a dependence of the period of stay from charge granularity in "calcination" zone calculated based on theoretical values.

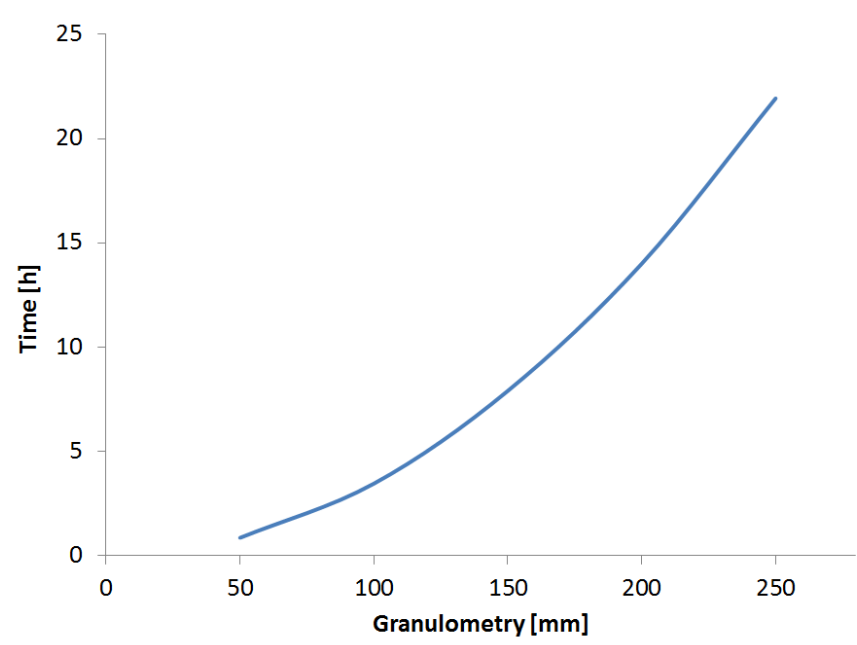

Figure 7. Influence of the grains size on the calcination time.

From Figure 7 it is obvious strong influence of the grain size on calcination time. This fact indicates the need of reducing inhomogeneity of granulometry of charge to optimize thermal processing of magnesite including calcination and sintering. Grain size homogeneity will lead to increase of charge permeability thereby to increasing of heat transfer.

\section{CONCLUSION}

Created mathematical model of the granular material thermal treatment was adapted to the real conditions by calibration and parameters determination. Simulations confirmed strong influence of the grains size on the calcination and sintering time. The obtained dependence we can explicitly use for the time setting with respect to the maximum grain size. In this way an appropriate heating time is provided in order to achieve the desired degree of sintering by using the dimensionless model. The model is developed for real time model based control. 


\section{ACKNOWLEDGEMENTS}

This contribution/publication is the result of the project implementation Advanced technology for the mining company of 21 st century supported by the Research \& Development Operational Programme funded by the ERDF. (ITMS: 26220220131)

\section{REFERENCES}

[1] Koštial, I., et al. 2005. Behavioural modelling of complex thermal systems. In Miskolc, Hungary, 6th International Carpathian Control Conference: 297-302.

[2] Kostial, I., et al. 2008. Advanced process manipulation of magnesia sintering. In.: Seoul, Korea, Proceedings of the 17th World Congress, The International Federation of Automatic Control: 718-723.

[3] Koštial, I. et al 2013. Simulation mathematical model for granular material thermal treatment. In Poland, 14th International Carpathian Control Conference: 150-153.

[4] Košinár, P. et al. 2011. Praxes needs in the area of research and development in SMZ, a.s. Jelšava, In Hrádok at Jelšava, Advance technologies of raw material mining and threatment: 228-232.

[5] Mikula, J. et al. 2009. Mathematical modelling of lumpy and granular material thermal treatment. Acta Metallurgica Slovaca 15(1): 197-204.

[6] Olijár, A. et al. 2011. Thermal sintering regimes and treatment regimes in the dependence of threaded material and requirements on the products. In Hrádok pri Jelšave, Advance technologies of raw material mining and treatment, 1st scientific symposium: 217-222. 